\title{
The Ductus Arteriosus, a Vascular Outsider, in Relation to the Pulmonary Circulation
}

\author{
Adriana C. Gittenberger-de Groot, Arno A. W. Roest, \\ Regina Bökenkamp, Monique R. M. Jongbloed, \\ Margot M. Bartelings, Marco C. DeRuiter, \\ and Robert E. Poelmann
}

\begin{abstract}
The muscular ductus arteriosus (DA) has many unique characteristics setting it apart from the adjoining elastic arteries. Preparation for neonatal closure takes place in utero with the development of intimal thickening. Ductus-specific gene and protein expression patterns were demonstrated during this process. We postulated that the closing process, with increased expression of progerin, might reflect aspects of premature ageing. Persistent patency of the DA, can be congenitally or immaturity based. During embryonic development the sixth pharyngeal arch arteries are the last to develop. In avian embryos this arch is divided into a proximal (part of the future pulmonary artery) and a distal part (on the left side the origin of the DA). The consequence is that the pulmonary arteries have a double vascular contribution being a proximal sixth arch artery component and
\end{abstract}

\footnotetext{
A. C. Gittenberger-de Groot $(\bowtie)$

Department of Cardiology, Leiden University Medical Center, Leiden, The Netherlands e-mail: acgitten@lumc.nl
}
A. A. W. Roest · R. Bökenkamp
Department of Pediatrics, Leiden University Medical Center, Leiden, The Netherlands
M. R. M. Jongbloed
Department of Cardiology, Leiden University Medical Center, Leiden, The Netherlands
Department of Anatomy and Embryology, Leiden University Medical Center,
Leiden, The Netherlands
M. M. Bartelings · M. C. DeRuiter
Department of Anatomy and Embryology, Leiden University Medical Center,
Leiden, The Netherlands
R. E. Poelmann
Department of Cardiology, Leiden University Medical Center, Leiden, The Netherlands
Department of Animal Sciences and Health, Leiden University, Leiden, The Netherlands

(C) The Editor(s) (if applicable) and The Author(s) 2020 
a distal true pulmonary artery segment. We have conclusive evidence that this is not encountered in the human embryo. Both sixth arch arteries and the right and left pulmonary arteries connect separately and at distinct locations to the pulmonary trunk side of the aortic sac. The insertion of the wall of the DA between the proximal and distal part of the left pulmonary artery, referred to as pulmonary coarctation, constitutes a congenital malformation and not a remnant of what is encountered during normal development. This configuration is found almost exclusively in combination with pulmonary atresia leading to neonatal interruption of the proximal left pulmonary artery with consequences for surgical or intervention repair.

\section{Keywords}

Vascular development · Patent ductus arteriosus - Persistent ductus arteriosus · Congenital heart disease $\cdot$ Pulmonary atresia $\cdot$ Pulmonary ductal coarctation · Juxtaductal pulmonary coarctation

\subsection{The Normal Closing Ductus Arteriosus}

The DA is a functional shunt before birth, directing oxygen-rich blood to the systemic circulation, bypassing the pulmonary circulation. Perinatally, the DA shows a physiological contraction followed by anatomical closure after birth. Eventually the closed DA is remodeled into a fibrous strand, the ligamentum arteriosum [1]. The characteristics of the muscular DA are reflected in its histological make-up, setting it apart from the elastic adjoining arteries [2]. Around 17 weeks of human gestation there is the start of formation of typical intimal thickenings (cushions). The first indication is the subendothelial appearance of hyaluronic acid and detachment of the endothelium [3]. The process of hyaluronic acid production continues during ductal maturation and even after birth [4]. In the second half of gestation the maturation process progresses and marked intimal thickenings develop containing media-derived synthetic smooth muscle cells and fine elastin fibers [5]. Accompanying the first physiological contractions the DA develops degeneration of the inner media, showing apoptosis and extracellular matrix filled mucoid lakes [5]. A recent study shows that this process is accompanied by a different lamin $\mathrm{A} / \mathrm{C}$ to progerin balance. Progerin, an indicator of vascular ageing, is increased in the mature DA [6]. This observation has lead us to postulate that a process akin to premature ageing might accompany postnatal ductal closure [6]. In Fig. 33.1, schematic and correlating histological features of the DA are presented.

More advanced methodology has allowed to shift focus to the unique gene and protein profiles of the DA. The data derive from DNA microarray profiling [7], transcriptional profiles [8] and gene profiling after single-cell microcapture isolation [9]. These studies unravel pieces of the puzzle underlying DA closure and maturation. Results show that the important relaxing factor, PGE2, inhibits elastogenesis, clarifying the muscular nature of the DA [10]. Furthermore the endothelin receptor EP4 promotes hyaluronic acid-induced intimal thickening [4]. 


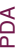
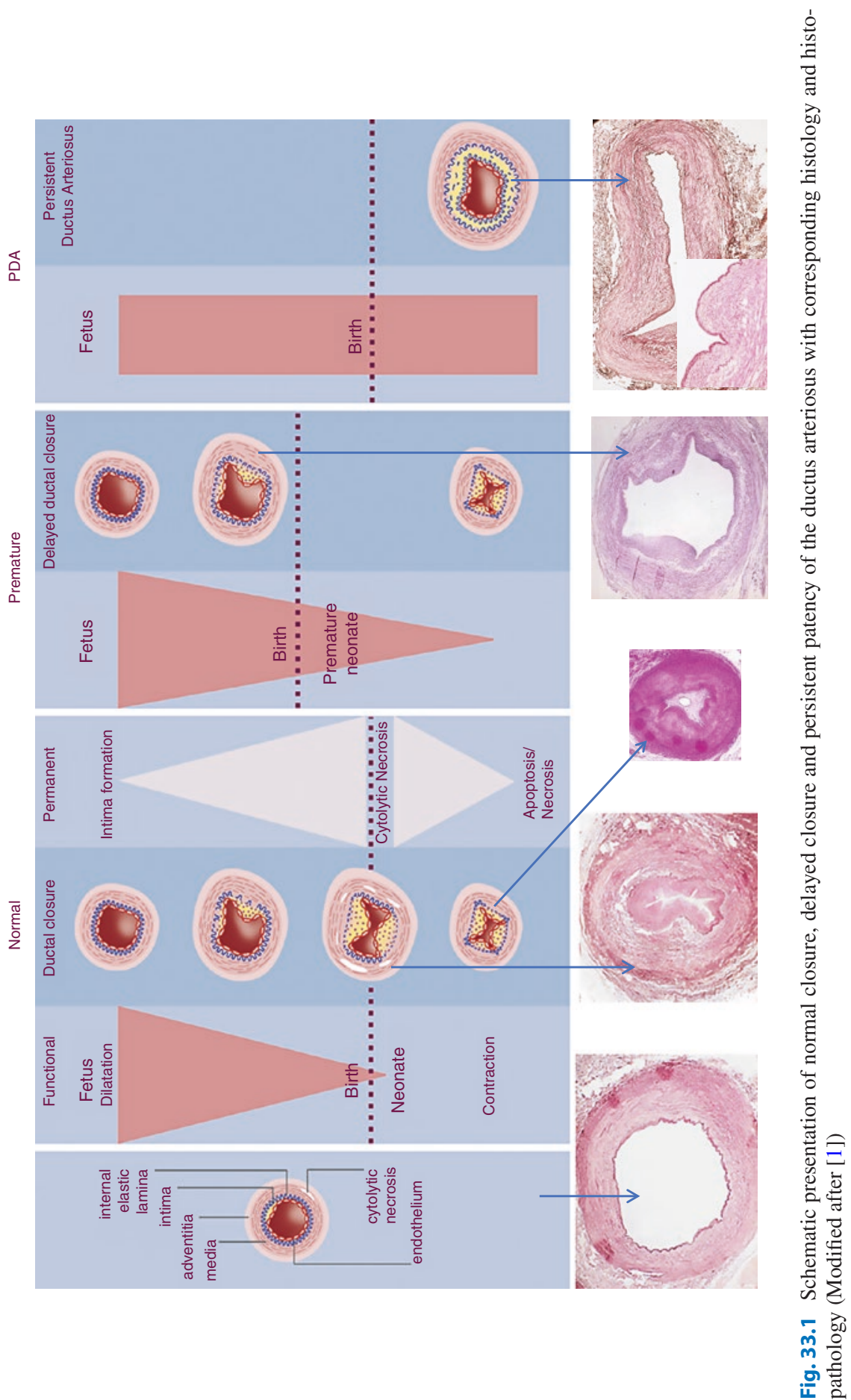

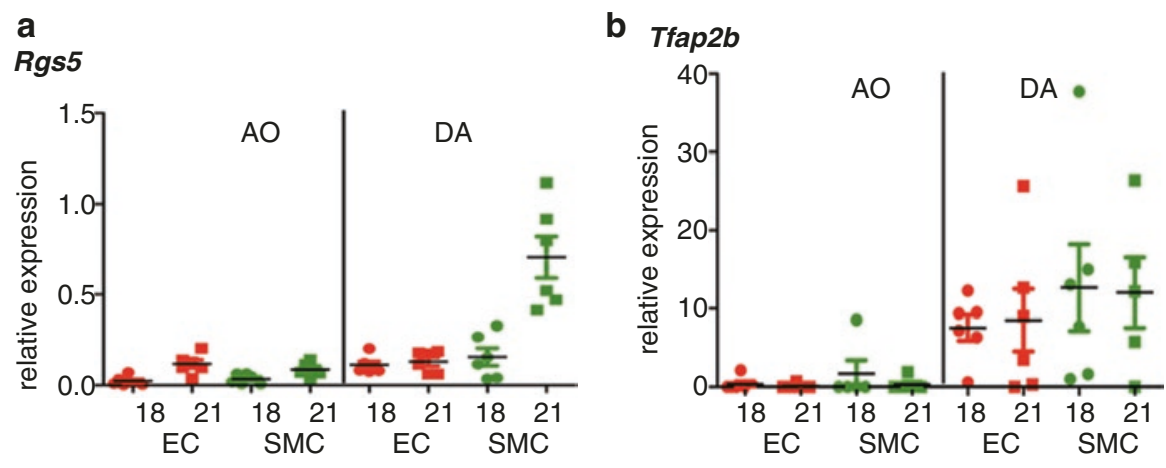

Fig. 33.2 Relative gene expression levels of Rgs5 and Tfap2B after microarray and quantitative RT-PCR, showing the differences between endothelial cells (EC: red) and smooth muscle cells (SMC: green) in aorta (Ao) and ductus arteriosus (DA) (Modified after [9])

With increased information, showing the distinct characteristics of smooth muscle and endothelial cells (Fig. 33.2) we gain insight into the pathological and delayed DA closure.

\subsection{Persistent Patency Versus Delayed Closure of the DA}

Several causes lead to a non-adequate to non-closure of the DA. The most common cause is delayed closure after premature birth because of immaturity of the ductal wall [5]. A different cause for ductal patency is a structural wall abnormality inhibiting anatomical closing. We have described that a DA with an additional and marked subendothelial elastic lamina (Fig. 33.1) is not capable of permanent anatomical closure [2]. As this anomaly can only be detected by histology, it poses a problem to differentiate it clinically from delayed closure. Very little is known about the genetic or environmental background of persistent DA. A few genes have been discovered like the TFAP2B gene mutation [11] that lead to persistent patency.

\subsection{Normal Sixth Pharyngeal Arch Formation and Connections to the Surrounding Arteries}

During development, pharyngeal arch arteries connect the aortic sac bilaterally to the dorsal aortae. The sixth arch, important for DA and pulmonary artery formation, has a separate status [12]. In various animal species it has been described that the putative left and right pulmonary arteries connect end to side to the sixth pharyngeal arch artery [13]. We have shown in quail embryos that this connection results from ingrowth of the pulmonary sprout into the sixth arch artery opposed to an outgrowth towards the lung mesenchyme [12]. This implies that the proximal part of the sixth arch artery forms the proximal part of the left pulmonary artery while the distal end develops the 
a

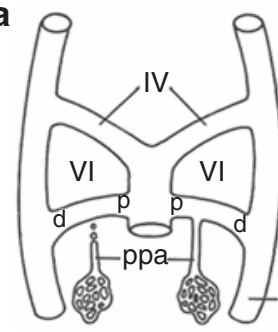

C

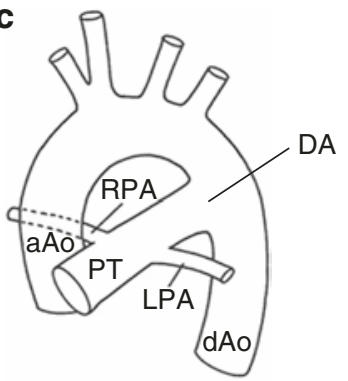

b

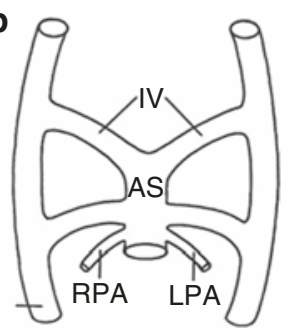

d

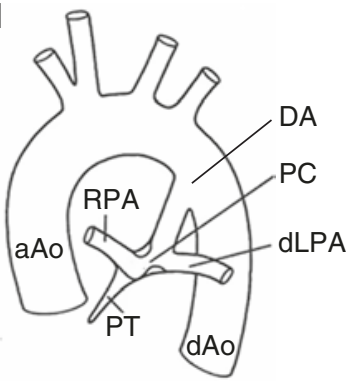

Fig. 33.3 (a) Schematic configuration of end-to-side ingrowth of pulmonary sprout (ppa) between the proximal (p) and distal (d) part of the sixth arch artery (VI). (b) Situation as encountered in a 6 week human embryo with right (RPA) and left (LPA) arteries connecting to the aortic sac (AS). (c) Normal neonatal situation with distinct connections of RPA, LPA and ductus arteriosus (DA) to the pulmonary trunk (PT). (d) Pulmonary coarctation (PC) in a case of pulmonary atresia. Ascending aorta $(\mathrm{aAo})$, descending aorta (dAo), fourth arch artery (IV)

characteristic DA structure. This necessitates a major remodeling process to achieve the mature situation in the human fetus and neonate in which the DA and left and right pulmonary arteries have a distinct connection site with the pulmonary trunk (Fig. 33.3). Investigation of human embryos, before 6 weeks of age, revealed that the ingrowth of the pulmonary arteries together with the proximal part of the sixth arch is incorporated into the pulmonary side of the aortic sac. Thus the distal part of the left-sided sixth pharyngeal artery develops into the left-sided DA. The distal right-sided sixth arch disappears together with the distal part of the right-sided dorsal aorta early in development by selective apoptosis [14]. These observations in the human embryo are relevant for understanding some forms of congenital heart disease and related complications.

\subsection{Pulmonary Coarctation (PC) and Proximal Left Pulmonary Artery Interruption}

DA problems can exist in right heart congenital heart disease with narrowing to atresia of the right ventricular outflow tract and hypoplasia of the pulmonary trunk. The most extreme is complete absence of the DA with the question whether a sixth arch artery ever developed. The VEGF120/120 mouse revealed that with increase of 
mild pulmonary stenosis towards complete atresia the DA became hypoplastic to atretic. In the most severe cases major aorto-pulmonary collateral arteries (MAPCAs) developed [15]. We published data on a set of human neonatal specimens with various degrees of pulmonary stenosis and atresia that had developed a PC [16]. We assumed that this anomaly mimicked the aortic coarctation in which DA tissue extends within the inner circumference of the aortic arch in which the roof of the coarctation always consisted of elastic aorta tissue (Fig. 33.2). More recent observations showed that PDC could lead to a complete obstruction of the proximal left pulmonary artery. DA tissue was, however, not only observed on the inside lining of the pulmonary artery but could completely encircle the lumen [17], being thus interposed between the proximal and distal part of the left pulmonary artery. Progressive narrowing by DA tissue could result in left pulmonary artery interruption. We concluded that a more left lateral insertion of the DA into the left pulmonary artery is not a normal position but a congenital anomaly. Reversed hemodynamics through the DA might play a secondary role as cause for PC.

\subsection{Future Directions and Clinical Implications}

- Is PC exclusively linked to anomalies with pulmonary atresia or can it also be associated with less severe obstructions of the right ventricular outflow tract and pulmonary valve?

- Is there a link to the $22 \mathrm{q} 11$ deletion syndrome and thus to mutations within the second heart field and its interaction with neural crest cells?

- A clinical implication of the complete encircling of the DA tissue of the left pulmonary artery is that by surgical restoration of the left pulmonary artery it should be aimed to completely excise the DA tissue or completely stent the DA-infested region.

\section{References}

1. Bökenkamp R, DeRuiter MC, VanMunsteren C, et al. Insights into the pathogenesis and genetic background of patency of the ductus arteriosus. Neonatology. 2010;98:6. https://doi. org/10.1159/000262481.

2. Gittenberger-de Groot AC. Persistent ductus arteriosus: most probably a primary congenital malformation. Br Heart J. 1977;39:610-8.

3. De Reeder EG, Girard N, Poelmann RE, et al. Hyaluronic acid accumulation and endothelial cell detachment in intimal thickening of the vessel wall; the normal and genetically defective ductus arteriosus. Am J Pathol. 1988;132:574-85.

4. Yokoyama U, Minamisawa S, Quan $\mathrm{H}$, et al. Chronic activation of the prostaglandin receptor EP4 promotes hyaluronan-mediated neointimal formation in the ductus arteriosus. J Clin Invest. 2006;116:3026-34.

5. Gittenberger-de Groot AC, van Ertbruggen I, Moulaert AJ, et al. The ductus arteriosus in the preterm infant: histologic and clinical observations. J Pediatr. 1980;96:88-93. 
6. Bökenkamp R, Raz V, Lie-Venema A, et al. Differential temporal and spatial progerin expression during closure of the ductus arteriosus in neonates. PLoS One. 2011;6:e23975. https://doi. org/10.1371/journal.pone.0023975.

7. Jin MH, Yokoyama U, Sato Y, et al. DNA microarray profiling identified a new role of growth hormone in vascular remodeling of rat ductus arteriosus. J Physiol Sci. 2011;61:167. https:// doi.org/10.1007/s12576-011-0133-3.

8. Liu NM, Yokota T, Maekawa S, et al. Transcription profiles of endothelial cells in the rat ductus arteriosus during a perinatal period. PLoS One. 2013;8:e73685. https://doi.org/10.1371/ journal.pone.0073685.

9. Bökenkamp R, van Brempt R, VanMunsteren JC, et al. Dlx1 and Rgs5 in the ductus arteriosus: vessel-specific genes identified by transcriptional profiling of laser-capture microdissected endothelial and smooth muscle cells. PLoS One. 2014;9:e86892. https://doi.org/10.1371/journal.pone.0086892.

10. Yokoyama U, Minamisawa S, Shioda A, et al. Prostaglandin E2 inhibits elastogenesis in the ductus arteriosus via EP4 signaling. Circulation. 2014;129:487. https://doi.org/10.1161/ CIRCULATIONAHA.113.004726.

11. Ivey KN, Sutcliffe D, Richardson J, et al. Transcriptional regulation during development of the ductus arteriosus. Circ Res. 2008;103:388. https://doi.org/10.1161/ CIRCRESAHA.108.180661.

12. DeRuiter MC, Gittenberger-de Groot AC, Poelmann RE, et al. Development of the pharyngeal arch system related to the pulmonary and bronchial vessels in the avian embryo. With a concept on systemic-pulmonary collateral artery formation. Circulation. 1993;87:1306-19.

13. Bergwerff M, DeRuiter MC, Gittenberger-de Groot AC. Comparative anatomy and ontogeny of the ductus arteriosus, a vascular outsider. Anat Embryol. 1999;200:559-71.

14. Molin DGM, DeRuiter MC, Wisse LJ, et al. Altered apoptosis pattern during pharyngeal arch artery remodelling is associated with aortic arch malformations in Tgf beta 2 knock-out mice. Cardiovasc Res. 2002;56:312-22.

15. Rammeloo LA, DeRuiter MC, van den Akker NM, et al. Development of major aorto-pulmonary collateral arteries in vegf120/120 isoform mouse embryos with tetralogy of Fallot. Pediatr Cardiol. 2015;36:89. https://doi.org/10.1007/s00246-014-0969-4.

16. Elzenga NJ, Gittenberger-de Groot AC. The ductus arteriosus and stenoses of the pulmonary arteries in pulmonary atresia. Int J Cardiol. 1986;11(2):195-208. https://doi. org/10.1016/0167-5273(86)90179-8.

17. Waldman JD, Karp RB, Gittenberger-de Groot AC, et al. Spontaneous acquisition of discontinuous pulmonary arteries. Ann Thorac Surg. 1996;62:161-8.

Open Access This chapter is licensed under the terms of the Creative Commons Attribution 4.0 International License (http://creativecommons.org/licenses/by/4.0/), which permits use, sharing, adaptation, distribution and reproduction in any medium or format, as long as you give appropriate credit to the original author(s) and the source, provide a link to the Creative Commons license and indicate if changes were made.

The images or other third party material in this chapter are included in the chapter's Creative Commons license, unless indicated otherwise in a credit line to the material. If material is not included in the chapter's Creative Commons license and your intended use is not permitted by statutory regulation or exceeds the permitted use, you will need to obtain permission directly from the copyright holder.

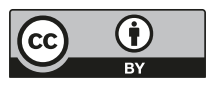

